\title{
A Photochemical Strategy for Carbon Isotope Exchange with $\mathrm{CO}_{2}$
}

Victor Babin, ${ }^{\dagger}$ Alex Talbot, ${ }^{\dagger}$ Alexandre Labiche, ${ }^{\dagger}$ Gianluca Destro, ${ }^{\dagger}$ Antonio Del Vecchio, ${ }^{\dagger}$ Charles S. Elmore ${ }^{\ddagger}{ }^{\text {Frédéric Taran }},{ }^{\dagger}$ Antoine Sallustrau, ${ }^{\dagger}$ Davide Audisio ${ }^{+*}$

${ }^{\dagger}$ Service de Chimie Bio-organique et Marquage (SCBM), CEA/DRF/JOLIOT, Université Paris Saclay, F91191, Gif-sur-Yvette, France. ${ }^{\ddagger}$ Isotope Chemistry, Pharmaceutical Science, R\&D, AstraZeneca, Gothenburg, Sweden

* davide.audisio@cea.fr

ABSTRACT: A novel photocatalytic approach for carbon isotope exchange is reported. Utilizing $\left[{ }^{13} \mathrm{C}\right] \mathrm{CO}_{2}$ as primary $\mathrm{C} 1$ sources, this protocol allows the insertion of the desired carbon isotope into phenyl acetic acids without the need of structural modifications or pre-functionalization, in one single step. The exceptionally mild conditions required for this traceless transformation are in stark contrast with previous methods requiring the use of harsh thermal conditions.

Developments in visible light photoredox catalysis have led to the invention of an ample array of chemical transformations, which would be either challenging or even impossible to perform under thermal conditions. Carbon-carbon bond formation represents a major challenge in photocatalysis and, in particular, the valorization of carbon dioxide $\left(\mathrm{CO}_{2}\right)$ is drawing much attention. Indeed, the functionalization of this one-carbon (C1) building block has implications that go far behind the scientific community, and affect the environment and our society as a whole. ${ }^{1{ }^{2}}{ }^{2}$ Recently, successful examples of photocatalytic $\mathrm{CO}_{2}$ functionalization have appeared. ${ }^{3,4,5}$

Besides valorizing this abundant greenhouse gas, these transformations are relevant in the field of carbon isotope labeling and particularly for carbon-14 $\left({ }^{14} \mathrm{C}\right)$, where $\left[{ }^{14} \mathrm{C}\right] \mathrm{CO}_{2}$ represents the primary source of radioisotope. ${ }^{6}{ }^{14} \mathrm{C}$ ( $\beta^{-}$emitter, half-life 5730 years) is the gold standard for the preparation of radiotracers utilized in human and veterinary absorption, distribution, metabolism, and excretion (ADME) determination, agrochemical and environmental fate studies. ${ }^{7}$ While ${ }^{14} \mathrm{C}$ has traditionally been introduced into biologically relevant target compounds in multi-step fashion (Figure $1 \mathrm{~A})$, drawbacks related to the limited available raw materials, their prohibitive costs $\left(\left[{ }^{14} \mathrm{C}^{\mathrm{C}}\right] \mathrm{CO}_{2}: 1600 €\right.$ per $\mathrm{mmol}$ ) and the generation of long-lasting waste are standing challenges. ${ }^{8}$

In the last couple of years, late-stage ${ }^{14} \mathrm{C}$-labeling has undergone sudden growth. ${ }^{9}$ In particular, carbon isotope exchange $(\mathrm{CIE})$, which allows for ${ }^{12} \mathrm{C}-{ }^{12} \mathrm{C}$ bond cleavage and ${ }^{12} \mathrm{C}-{ }^{14} \mathrm{C}$ bond formation in one single step, emerged as privileged strategy (Figure 1B). ${ }^{10}$ Mostly focused on $\left[{ }^{12} \mathrm{C}\right] /\left[{ }^{14} \mathrm{C}\right] \mathrm{CO}_{2}$ exchange, ${ }^{11,12,13}$ these methodologies are based on the use of transition metals, which are in some cases even required in stoichiometric amounts. ${ }^{14}$ In 2020, our group and Lundgren's independently reported the transition metal-free thermal CIE of phenyl acetic acids (PAA). ${ }^{15}$ By heating the corresponding cesium or potassium carboxylates in presence of labeled $\mathrm{CO}_{2}$, reversible decarboxylation/carboxylation takes place and the desired acids were obtained with good isotope incorporation. While appealing, the requirement of harsh thermal heating is compulsory for nonactivated PAAs. Prolonged heating at $160^{\circ} \mathrm{C}$ for $48 \mathrm{hrs}^{15}$ was required to label a series of well-known Non-Steroidal Anti-Inflammatory Drugs (NSAIDs), such as Ibuprofen, Fenoprofen, Ketoprofen, Naproxen and Diclofenac. ${ }^{16}$ Drastic conditions for an extended period of time are generally unsuitable, and especially when handling of radioactive materials is involved. 
A Previous multi-step methods:
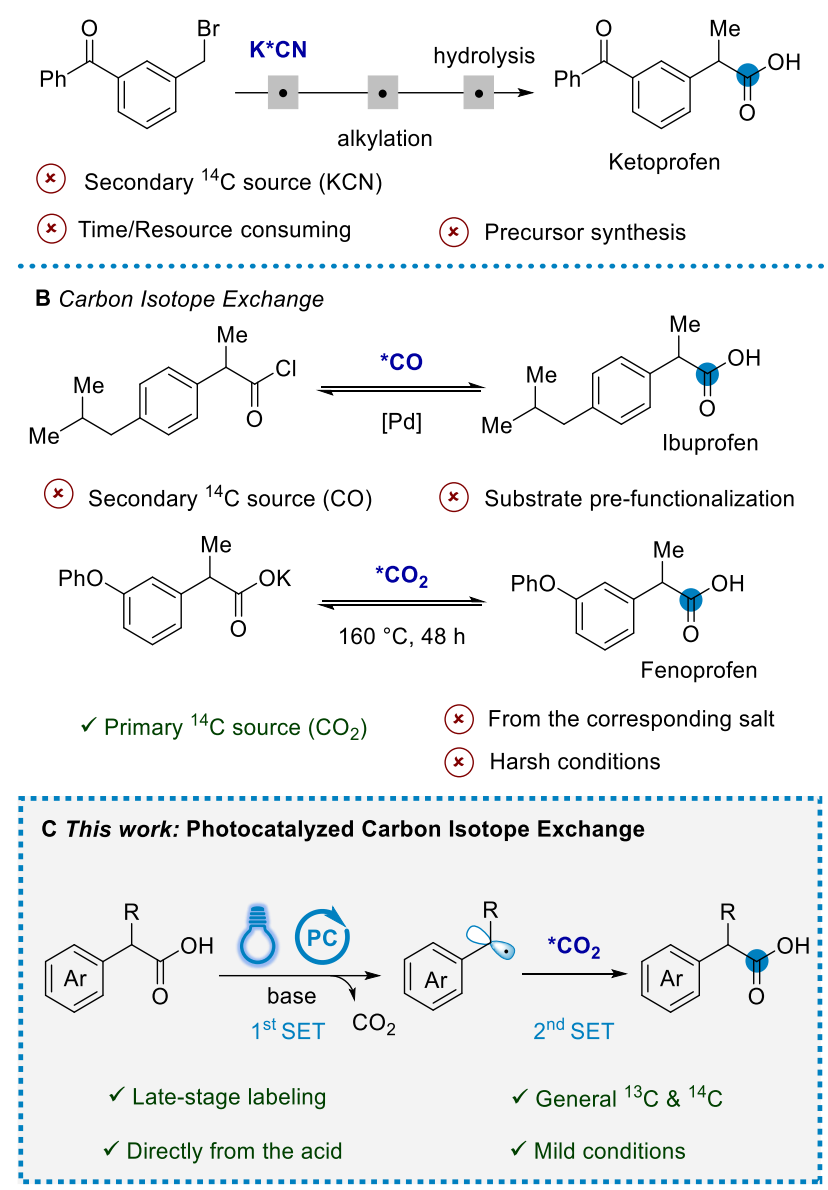

Figure 1: State of the art. (A) Multi-step carbon labeling technologies for the insertion of the isotope into a pharmaceutically relevant PAA. (B) Reported CIE procedures. (C) Photocatalytic CIE. Blue circles represent the positions of isotopically labeled carbon. $\mathrm{PC}=$ photocatalyst; $\mathrm{SET}=$ single electron transfer.

The invention of a reversible carboxylation process under mild conditions still constitutes a fundamental challenge. Herein, we report the first photocatalytic approach for carbon isotope exchange (Figure 1C). This protocol allows the insertion of the desired isotope into phenyl acetic acids, including non-natural phenyl glycine amino acids, at $42{ }^{\circ} \mathrm{C}$ only and without the need of structural modifications or pre-functionalization. These exceptionally mild conditions stand in stark contrast with previous methods requiring the use of brutal thermal force. ${ }^{17}$

The optimized reaction conditions for the photocatalytic CIE of carboxylic acids are shown in Table 1. Model substrate 2-phenylacetic acid 1 was labeled in $72 \%$ isolated yield and $47 \%$ isotopic enrichment (IE), in presence of the photocatalyst (PC) $4 \mathrm{CZIPN}(6 \mathrm{~mol} \%), \mathrm{K}_{3} \mathrm{PO}_{4}$ and $\left[{ }^{13} \mathrm{C} \mathrm{CO}_{2}\right.$ as a convenient surrogate for $\left[{ }^{14} \mathrm{C}\right] \mathrm{CO}_{2}$ in dry DMF within 6 hours. The reactions were performed employing $0.1 \mathrm{mmol}$ of substrate and $0.3 \mathrm{mmol}$ of $\left[{ }^{13} \mathrm{C}\right] \mathrm{CO}_{2}$ were precisely added using the RC Tritec manifold. ${ }^{18} \mathrm{~A}$ higher IE of $62 \%$ was obtained by increasing the catalyst load to 12 mol\% (entry 2), but the isolated yield diminished to $43 \%$, while proto-decarboxylation side-product $\mathbf{1 b}$ was formed in $47 \%$. Under the reaction conditions, we noticed that PC $\mathbf{2}$ was entirely converted into $\mathbf{3}(4 \mathrm{CZBnBN})$, which is likely to 
be the active PC in the reaction. This observation is in agreement with previous reports by König and Tunge. ${ }^{19}$ Notably, the use of other photocatalysts resulted in low isotope incorporation (SI, Table S4), while only 3 provided comparable results (entry 3). To exclude PC degradation over the reaction condition, $\mathbf{3}$ was isolated from the crude mixture and successfully reengaged in photocatalytic CIE (see Table S4 SI for details). Other bases such as $\mathrm{K}_{2} \mathrm{CO}_{3}$ and $\mathrm{CsOAc}$ were also compatible but gave lower IE (Table 1, entries 4, 5 and Table S3), while the absence of the base resulted in no reaction (Table 1, entry 6). The use of carbonate bases was excluded to avoid isotope dilution, as potential source of unlabeled $\left[{ }^{12} \mathrm{C}\right] \mathrm{CO}_{2}{ }^{5 a, 5 d, 20}$ When the reaction was performed starting from the corresponding potassium carboxylate $\left[{ }^{13} \mathrm{C}\right] 1$ was obtained in $50 \%$ IE and $94 \%$ yield (see $\mathrm{SI}$ ). The use of other polar aprotic solvent such as DMSO provided $\left[{ }^{13} \mathrm{C}\right] \mathbf{1}$ in $66 \% \mathrm{IE}$, but drastically eroded the yield (entry 6 and Table S2). When $\left[{ }^{13} \mathrm{C}\right] \mathrm{CO}_{2}$ was replaced by nitrogen complete proto-decarboxylation was observed (Table 1, entry 8). Finally, removing 4CzIPN from the reaction or the absence of light resulted in no isotope incorporation, showcasing that no background reaction occurs on non-activated substrate (Table 1, entries 9 and 10).

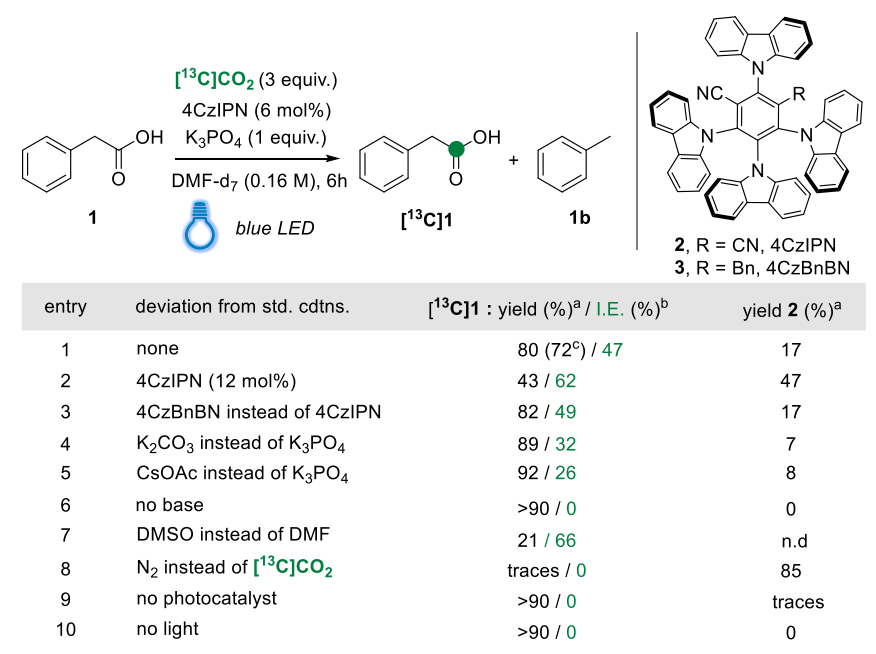

Table 1: Optimization of the reaction. ${ }^{a}$ Yields were determined from the crude ${ }^{1} \mathrm{H}$ NMR spectra using 1,3,5- trimethoxybenzene as an internal standard. ${ }^{b}$ Isotopic enrichments (I.E.) were determined by mass spectrometry. ${ }^{\mathrm{C}}$ Isolated yield. The temperature of the reaction was to $42 \pm 2{ }^{\circ} \mathrm{C}$.

With these optimized conditions in hand, we directed our studies toward the scope (Figure 2). Regardless to the position, in presence of electron donating groups on the aromatic ring, isotopic enrichment was observed in substituted phenyl acetic acids bearing alkyl $\left[{ }^{13} \mathrm{C}\right] 4-5$ or methoxy $\left[{ }^{13} \mathrm{C}\right]$ 6-9 moieties. It is worth to note that higher incorporation was achieved with ortho substitution but a lower isolated yield was obtained $\left(\left[{ }^{13} \mathrm{C}\right] 8, \mathrm{IE}=71 \%, 29 \%\right.$ yield $)$. Halogen were also tolerated and $\left[{ }^{13} \mathrm{C}\right] \mathbf{1 0}-16$ were labeled in 29 to $70 \% \mathrm{IE}$ and good yields. Only substrate $\mathbf{1 3}$ could not be labeled and de-iodination occurred without insertion of ${ }^{13} \mathrm{C}$ in the acid. Investigation with stronger electro-withdrawing groups led to successful labeling of various substrates such as trifluoromethyl $\left[{ }^{13} \mathrm{C}\right] 17-19$ (IE $\left.=33-70 \%\right), m$ nitrile $\left[{ }^{13} \mathrm{C}\right] 20(\mathrm{IE}=64 \%)$ and ester derivatives $\left[{ }^{13} \mathrm{C}\right] 21(\mathrm{IE}=63 \%)$. Importantly, on this electron poor substrates no background reaction is observed in the absence of PC. ${ }^{15 b}$ Labeling of dicarboxylic acids 22-23 required using DMSO in place of DMF, for solubility reasons, and 2 equiv. of base. Interestingly, $\left[{ }^{13} \mathrm{C}\right] 22$ was selectively labeled in $30 \% \mathrm{IE}$, while for $\left[{ }^{13} \mathrm{C}\right] \mathbf{2 3}$ only a single label was recovered (IE $15 \%$ ). 


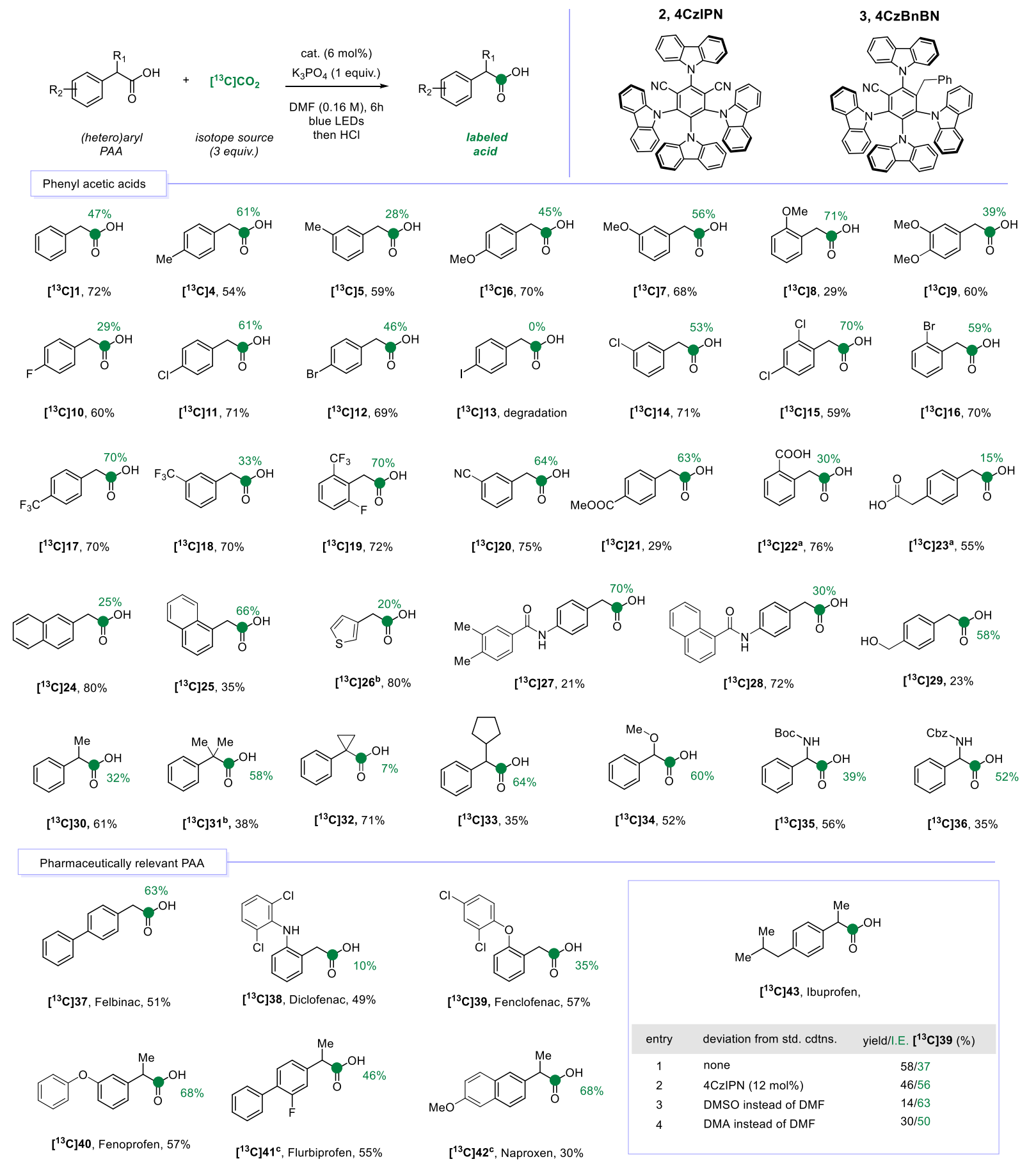

Figure 2: Photocatalyzed CIE labeling of phenyl acetic acids and pharmaceutical compounds. Green colored circles and numbers denote the positions of the carbon atoms labeled and the percent incorporation of the carbon isotope. DMF, $\mathrm{N}, \mathrm{N}$-dimethylformamide. [a] Using 2 equiv. of $\mathrm{K}_{3} \mathrm{PO}_{4}$ and DMSO instead of DMF. [b] ${ }^{1} \mathrm{H}$ NMR yield determined using DMF-d7 instead of DMF and 1,3,5trimethoxybenzene as internal standard. [c] Reaction time: $3 \mathrm{~h}$ instead of $6 \mathrm{~h}$. The temperature of the reaction was to $42 \pm 2{ }^{\circ} \mathrm{C}$.

It is worth noting that isotope incorporation was also possible in the presence of labile protons such as amide or alcohol [ $\left.{ }^{13} \mathrm{C}\right] \mathbf{2 7}-\mathbf{2 9}$ (IE $=40-70 \%$ and $21-72 \%$ yield). Pleasingly, functionalization in benzylic position was not detrimental for the reaction and applying the procedure to such substrates could 
afford the expected labeled phenyl acetic acids. The presence of alkyl substituents $\alpha$ to the carboxylic acid was tolerated $\left[{ }^{13} \mathrm{C}\right] \mathbf{3 0}-\mathbf{3 3}$. While the gem-dimethyl $\mathbf{3 1}$ was effectively labeled, the presence of a cyclopropyl ring allowed only minimal exchange $\left(\left[{ }^{13} \mathrm{C}\right] 32 \mathrm{IE}<7 \%\right)$. CIE was performed on particularly challenging non-natural protected amino acids $\left[{ }^{13} \mathrm{C}\right] 35-36$ and successfully enable the exchange in 39 to $52 \%$ IE.

Next, we turned our attention to the labeling of pharmaceutically relevant derivatives, Felbinac $\left[{ }^{13} \mathrm{C}\right] 37$ was labeled with an isotopic enrichment of $63 \%$ and $51 \%$ yield. Diclofenac 38 and Fenclofenac 39 were obtained respectively in $49 \%$ and $57 \%$ of recovered products with $10 \%$ and $35 \%$ of isotope incorporation. The structural similarity of these drugs shows that the presence of an aniline in ortho position to the acid have a deleterious effect on both IE and yield. Fenoprofen $\mathbf{4 0}$ was labeled with $68 \%$ of IE and a correct isolated yield of $57 \%$. To obtain labeled $\mathbf{4 1}$ and $\mathbf{4 2}$ in useful recovered amounts and avoid extensive proto-decarboxylation, a slight modification of the conditions was required. Reducing the time of the reaction from 6 to 3 hours allowed to isolate Flurbiprofen $\left[{ }^{13} \mathrm{C}\right] 41$ and Naproxen $\left[{ }^{13} \mathrm{C}\right] 42$ with $46 \%$ and $68 \%$ of isotopic incorporations and $55 \%$ to $30 \%$ yields, respectively.

An optimization of the reaction was performed to effectively label the most notorious NSAID on the market Ibuprofen 43. It was found that the use $12 \mathrm{~mol} \%$ of PC allowed an enhancement of the isotopic incorporation with a minor modification of the final isolated yield (IE $=56 \%, 46 \%)$. The utilization of other polar non protic solvents (DMSO and DMA) drastically reduced the isolated yield.

In conclusion, we developed the first photocatalytic carbon isotope procedure for the carbon labeling of phenyl acetic acids. This reaction proceeds under exceptionally mild reaction conditions compared to previous $\mathrm{CIE}$ technologies and provides a complementary approach to the challenging carbon labeling of pharmaceuticals. Implementation of this novel transformation towards radioactive ${ }^{14} \mathrm{C}$ radiolabeling is currently ongoing in our laboratory.

\section{Acknowledgments}

This work was supported by CEA and by the European Union's Horizon 2020 research and innovation program under the Marie Sklodowska-Curie grant agreement $\mathrm{N}^{\circ} 675071$, the European Research Council (ERC-2019-COG - 864576) and FET-OPEN No 862179. The authors thank A. Goudet, S. Lebrequier and D.-A. Buisson (DRF-JOLIOT-SCBM, CEA) for the excellent analytical support.

\section{References}

[1] (a) Aresta, M.; Dibenedetto, A.; Angelini, A., Catalysis for the Valorization of Exhaust Carbon: from $\mathrm{CO}_{2}$ to Chemicals, Materials, and Fuels. Technological Use of $\mathrm{CO}_{2}$. Chem. Rev. 2014, 114, 1709-1742. (b) Civiš S., Ferus M., Knižek A. (2019) Carbon Dioxide and the Effects on Climate. In: The Chemistry of $\mathrm{CO}_{2}$ and TiO2. SpringerBriefs in Molecular Science. Springer, Cham. https://doi.org/10.1007/978-3030-24032-5_1.

[2] For a non-comprehensive series of reviews in the field, see: (a) Börjesson, M.; Moragas, T.; Gallego, D.; Martin, R., Metal-Catalyzed Carboxylation of Organic (Pseudo)halides with $\mathrm{CO}_{2}$. ACS Catal. 2016, 6, 6739-6749. (b) Wang, S.; Xi, C., Recent advances in nucleophile-triggered $\mathrm{CO}_{2}$-incorporated cyclization leading to heterocycles. Chem. Soc. Rev. 2019, 48, 382-404. (c) Liu, Q.; Wu, L.; Jackstell, R.; Beller, M., Using carbon dioxide as a building block in organic synthesis. Nat. Commun. 2015, 6, 5933. (d) Huang, K.; Sun, C.-L.; Shi, Z.-J., Transition-metal-catalyzed C-C bond formation through the fixation of carbon 
dioxide. Chem. Soc. Rev. 2011, 40, 2435-2452. (e) Yang, Y.; Lee, J.-W., Toward ideal carbon dioxide functionalization. Chem. Sci. 2019, 10, 3905-3926. (f) Juliá-Hernández, F.; Gaydou, M.; Serrano, E.; van Gemmeren, M.; Martin, R., Ni- and Fe-catalyzed Carboxylation of Unsaturated Hydrocarbons with $\mathrm{CO}_{2}$. Top. Cur. Chem. 2016, 374, 45.

[3] For recent reviews, see: (a) Yeung, C. S., Photoredox Catalysis as a Strategy for $\mathrm{CO}_{2}$ Incorporation: Direct Access to Carboxylic Acids from a Renewable Feedstock. Angew. Chem. Int. Ed. 2019, 58, 54925502. (b) He, X.; Qiu, L.-Q.; Wang, W.-J.; Chen, K.-H.; He, L.-N., Photocarboxylation with $\mathrm{CO}_{2}$ : an appealing and sustainable strategy for $\mathrm{CO}_{2}$ fixation. Green Chem. 2020, DOI: 10.1039/D0GC02743J.

[4] For photocatalytic carboxylations of styrenes, see : (a) Yatham, V. R.; Shen, Y.; Martin, R., Catalytic Intermolecular Dicarbofunctionalization of Styrenes with $\mathrm{CO}_{2}$ and Radical Precursors. Angew. Chem. Int. Ed. 2017, 56, 10915-10919. (b) Ju, T.; Fu, Q.; Ye, J.-H.; Zhang, Z.; Liao, L.-L.; Yan, S.-S.; Tian, X.-Y.; Luo, S.-P.; Li, J.; Yu, D.-G., Selective and Catalytic Hydrocarboxylation of Enamides and Imines with $\mathrm{CO}_{2}$ to Generate $\alpha, \alpha$-Disubstituted $\alpha$-Amino Acids. Angew. Chem. Int. Ed. 2018, 57, 13897-13901. (c) Hou, J.; Ee, A.; Cao, H.; Ong, H.-W.; Xu, J.-H.; Wu, J., Visible-Light-Mediated Metal-Free Difunctionalization of Alkenes with $\mathrm{CO}_{2}$ and Silanes or $\mathrm{C}(\mathrm{sp} 3)-\mathrm{H}$ Alkanes. Angew. Chem. Int. Ed. 2018, 57, 17220-17224. (d) Seo, H.; Liu, A.; Jamison, T. F., Direct $\beta$-Selective Hydrocarboxylation of Styrenes with $\mathrm{CO}_{2}$ Enabled by Continuous Flow Photoredox Catalysis. J. Am. Chem. Soc. 2017, 139, 13969-13972. (e) Liao, L.-L.; Cao, G.-M.; Ye, J.-H.; Sun, G.-Q.; Zhou, W.-J.; Gui, Y.-Y.; Yan, S.-S.; Shen, G.; Yu, D.-G., Visible-LightDriven External-Reductant-Free Cross-Electrophile Couplings of Tetraalkyl Ammonium Salts. J. Am. Chem. Soc. 2018, 140, 17338-17342. (f) Meng, Q.-Y.; Schirmer, T. E.; Berger, A. L.; Donabauer, K.; König, B., Photocarboxylation of Benzylic C-H Bonds. J. Am. Chem. Soc. 2019, 141, 11393-11397. (g) Wang, H.; Gao, Y.; Zhou, C.; Li, G., Visible-Light-Driven Reductive Carboarylation of Styrenes with $\mathrm{CO}_{2}$ and Aryl Halides. J. Am. Chem. Soc. 2020, 142, 8122-8129.

[5] (a) Meng, Q.-Y.; Wang, S.; König, B., Carboxylation of Aromatic and Aliphatic Bromides and Triflates with $\mathrm{CO}_{2}$ by Dual Visible-Light-Nickel Catalysis. Angew. Chem. Int. Ed. 2017, 56, 13426-13430. (b) Ye, J.-H.; Miao, M.; Huang, H.; Yan, S.-S.; Yin, Z.-B.; Zhou, W.-J.; Yu, D.-G., Visible-Light-Driven IronPromoted Thiocarboxylation of Styrenes and Acrylates with $\mathrm{CO}_{2}$. Angew. Chem. Int. Ed. 2017, 56, 15416-15420. (c) Ishida, N.; Masuda, Y.; Imamura, Y.; Yamazaki, K.; Murakami, M., Carboxylation of Benzylic and Aliphatic $\mathrm{C}-\mathrm{H}$ Bonds with $\mathrm{CO}_{2}$ Induced by Light/Ketone/Nickel. J. Am. Chem. Soc. 2019, 141, 19611-19615. (d) Song, L.; Fu, D.-M.; Chen, L.; Jiang, Y.-X.; Ye, J.-H.; Zhu, L.; Lan, Y.; Fu, Q.; Yu, D.G., Visible-Light Photoredox-Catalyzed Remote Difunctionalizing Carboxylation of Unactivated Alkenes with $\mathrm{CO}_{2}$. Angew. Chem. Int. Ed. 10.1002/anie.202008630.

[6] Kamen, M. D. Early History of Carbon-14: Discovery of this Supremely Important Tracer Was Expected in the Physical Sense but Not in the Chemical Sense. Science, 1963, 140, 584-590.

[7] (a) Isin, E. M.; Elmore, C. S.; Nilsson, G. N.; Thompson, R. A.; Weidolf, L. Use of Radiolabeled compounds in drug metabolism and pharmacokinetic studies. Chem. Res. Toxicol. 2009, 25, 532-542. (b) Elmore, C. S.; Bragg, R. A. Isotope chemistry; a useful tool in the drug discovery Arsenal. Bioorg. Med. Chem. Lett. 2015, 25, 167-171. (c) Marathe, P. H.; Shyu, W. C.; Humphreys, W. G. The Use of radiolabeled compounds for ADME studies in discovery and exploratory development. Curr. Pharm. Des. 2004, 10, 2991-3008. (d) Maxwell, B. D.; Elmore, C. S. Eds. Radiosynthesis for ADME studies; 461471 (John Wiley \& Sons, Inc: Hoboken, 2012). (e) Elmore, C. S., The use of isotopically labeled compounds in drug discovery. Ed. Annu. Rep. Med. Chem. 2009, 44, 515-534.

[8] Voges, R.; Heys, J. R.; Moenius, T. Preparation of Compounds Labeled with Tritium and Carbon-14 (John Wiley \& Sons, 2009). 
[9] For examples of late-stage ${ }^{14} \mathrm{C}$ labeling, see : (a) Song, F.; Salter, R.; Chen, L. Development of decarboxylative cyanation reactions for $\mathrm{C}-13 / \mathrm{C}-14$ carboxylic acid labeling using an electrophilic cyanating reagent. J. Org. Chem. 2017, 82, 3530-3537. (b) Del Vecchio, A.; Caillé, F.; Chevalier, A.; Loreau, O.; Horkka, K.; Halldin, C.; Schou, M.; Camus, N.; Kessler, P.; Kuhnast, B.; Taran, F.; Audisio, D. Late-Stage Isotopic Carbon Labeling of Pharmaceutically Relevant Cyclic Ureas Directly from $\mathrm{CO}_{2}$. Angew. Chem. Int. Ed., 2018, 57, 9744-9748. (c) Donslund, A. S.; Pedersen, S. S.; Gaardbo, C.; Neumann, K. T.; Kingston, L.; Elmore, C. S.; Skrydstrup, T., Direct Access to Isotopically Labeled Aliphatic Ketones Mediated by Nickel(I) Activation. Angew. Chem. Int. Ed. 2020, 59, 8099-8103. (d) Del Vecchio, A.; Talbot, A.; Caillé, F.; Chevalier, A.; Sallustrau, A.; Loreau, O.; Destro, G.; Taran, F.; Audisio, D., Carbon Isotope Labeling of Carbamates by Late-Stage $\left[{ }^{11} \mathrm{C}\right],\left[{ }^{13} \mathrm{C}\right]$ and $\left[{ }^{14} \mathrm{C}\right]$ Carbon Dioxide Incorporation. Chem. Commun. 2020, 10.1039/DOCC05031H.

[10] Hinsinger, K.; Pieters, G. The emergence of carbon isotope exchange. Angew. Chem. Int. Ed. 2019, $58,9678-9680$.

[11] (a) D. Audisio, T. Cantat, G. Destro, EP18305407 (2018); WO 2019/193068 A1. (b) Destro, G.; Loreau, O.; Marcon, E.; Taran, F.; Cantat, T.; Audisio. D.; Dynamic carbon isotope exchange of pharmaceuticals with labeled $\mathrm{CO}_{2}$. J. Am. Chem. Soc. 2019, 141, 780-784. (c) Tortajada, A.; Duan, Y.; Sahoo, B.; Cong, F.; Toupalas,G.; Sallustrau, A.; Loreau, O.; Audisio, D.; Martin, R. Catalytic decarboxylation/carboxylation platform for accessing isotopically labeled carboxylic acids. ACS Catal. 2019, 9, 5897-5901.

[12] For ClE using ${ }^{14} \mathrm{C}$-carbon monoxide starting from acid chlorides, see : Gauthier, Jr. D. R.; Rivera, N. L.; Yang, Y.; Schultz, D. M.; Shultz, C. S. Palladium-catalyzed carbon isotope exchange on aliphatic and benzoic acid chlorides. J. Am. Chem. Soc. 2018, 140, 15596-15600.

[13] For an early example of CIE procedure using strong basic conditions (LDA) in presence of HMPA, see : a) Parnes, H. A method for the preparation of ${ }^{14} \mathrm{C}$-labeled carboxylic acids. Synthesis of 6,11dihydro[b,e]thiepin-11-one-3-yl acetic ${ }^{14} \mathrm{C}$-acid. J. Label. Compd. Radiopharm. 1979, 16, 771-775.

[14] For an example of CIE using stoichiometric amounts of nickel, see : Kingston, C.; Wallace, M. A.; Allentoff, A. J.; deGruyter, J. N.; Chen, J. S.; Gong, S. X.; Bonacorsi, Jr., S.; Baran., P., S.; Direct carbon isotope exchange through decarboxylative carboxylation. J. Am. Chem. Soc. 2019, 141, 774-779.

[15] (a) Destro, G.; Horkka, K.; Loreau, O.; Buisson, D.-A.; Kingston, L.; Del Vecchio, A.; Schou, M.; Elmore, C. S.; Taran, F.; Cantat, T.; Audisio, D., Transition-Metal-Free Carbon Isotope Exchange of Phenyl Acetic Acids. Angew. Chem. Int. Ed. 2020, 59 (32), 13490-13495. (b) Kong, D.; Moon, P. J.; Lui, E. K. J.; Bsharat, O.; Lundgren, R. J., Direct reversible decarboxylation from stable organic acids in dimethylformamide solution. Science 2020, 369, 557-561.

[16] For multi-step labeling of PAAs, see: (a) Horio, Y.; Torisawa, Y.; Ikegami. S. A synthesis of ${ }^{14} \mathrm{C}-$ labeled sodium 2-[o-[2,6-dichlorophenyl)-amino]phenyl]acetate $\left(\left[{ }^{14} \mathrm{C}\right]\right.$ diclofenac sodium). Chem. Pharm. Bull. 1985, 33, 5562-5564. (b) Hayball, P.J.; Nation, R.L.; Bochner, F.; Newton, J.L.; MassyWestropp, R.A.; Hamon, D.P.G. Plasma protein binding of ketoprofen enantiomers in man: method development and its application. Chirality, 1991, 3, 460-466. (c) Corrie, J. E. T.; Munasinghe, V. R. N. Preparation of [carboxy- ${ }^{13} \mathrm{C}$ ]-4-nitrophenylacetic acid. J. Label. Compd. Radiopharm. 2005; 48, 231233. (d) Shackleford, D. M.; Hayball, P. J.; Reynolds, G. D.; Hamon, D. P.; Evans, A. M.; Milne, R. W.; Nation, R. L. A small-scale synthesis and enantiomeric resolution of $(R, S)-\left[1-{ }^{14} \mathrm{C}\right]-2$-phenylpropionic acid and biosynthesis of its diastereomeric acyl glucuronides. J. Label. Compd. Radiopharm. 2001, 44, 225234. (e) Turnbull, LB.; Johnson III, CJ.; Chen, YH.; Sancilio, LF.; Bruce, RB.; Disposition and metabolism of 4-methyl-2-(4-phenylbenzyl)-2-oxazoline-4-methanol in the rat and dog. J. Med. Chem, 1974, 17, 
45-48. (f) Marsh, M.V.; Caldwell, J.; Sloan, T.P.; Smith, R.L.; The metabolism of fenclofenac in the horse. Xenobiotica, 1983, 13, 233-240.

[17] For exchange of carboxylate groups in simple aliphatic acids with labeled $\mathrm{CO}_{2}$ under extremely harsh, pyrolytic conditions $\left(290-440^{\circ} \mathrm{C}\right)$, see: (a) Szabolcs, A.; Szammer, J.; Noszkó, L. A new method for the preparation of carboxyl-labelled aliphatic carboxylic acids. Tetrahedron 1974, 30, 3647-3648. (b) Nakai, R.; Sugii, M.; Nakao, H., Isotopic Tracer Studies of the Ketonic Pyrolysis of Sodium Carboxylates. J. Am. Chem. Soc. 1959, 81, 1003-1006.

[18] Isotopic Enrichment was determined by mass spectrometry. In this study, the maximum theoretical IE is: 3 equiv. ${ }^{*} \mathrm{CO}_{2} /\left(3\right.$ equiv. ${ }^{*} \mathrm{CO}_{2}+1$ equiv. ${ }^{12} \mathrm{CO}_{2}$ substrate) $100=75 \%$.

[19] (a) Donabauer, K.; Maity, M.; Berger, A. L.; Huff, G. S.; Crespi, S.; König, B., Photocatalytic carbanion generation - benzylation of aliphatic aldehydes to secondary alcohols. Chem. Sci. 2019, 10, 5162-5166. (b) Cartwright, K. C.; Tunge, J. A., Organophotoredox/palladium dual catalytic decarboxylative Csp3Csp3 coupling of carboxylic acids and $\pi$-electrophiles. Chem. Sci. 2020, 11, 8167-8175.

[20] See references $5 \mathrm{a}$ and $5 \mathrm{~d}$ for exemples where carbonate bases, $\mathrm{K}_{2} \mathrm{CO}_{3}$ and $\mathrm{Cs}_{2} \mathrm{CO}_{3}$, have been shown to be souce of $\mathrm{CO}_{2}$ in photocatalytic carboxylations. 